\title{
Zidovudine, abacavir and lamivudine increase the radiosensitivity of human esophageal squamous cancer cell lines
}

\author{
XUAN CHEN, CONG WANG, SHANGHUI GUAN, YUAN LIU, LIHUI HAN and YUFENG CHENG \\ Department of Radiation Oncology, Qilu Hospital of Shandong University, Jinan, Shandong 250012, P.R. China
}

Received January 14, 2016; Accepted February 26, 2016

DOI: $10.3892 /$ or.2016.4819

\begin{abstract}
Telomerase is a type of reverse transcriptase that is overexpressed in almost all human tumor cells, but not in normal tissues, which provides an opportunity for radiosensitization targeting telomerase. Zidovudine, abacavir and lamivudine are reverse transcriptase inhibitors that have been applied in clinical practice for several years. We sought to explore the radiosensitization effect of these three drugs on human esophageal cancer cell lines. Eca109 and Eca9706 cells were treated with zidovudine, abacavir and lamivudine for $48 \mathrm{~h}$ before irradiation was administered. Samples were collected $1 \mathrm{~h}$ after irradiation. Clonal efficiency assay was used to evaluate the effect of the combination of these drugs with radiation doses of 2, 4, 6 and 8 Gy. DNA damage was measured by comet assay. Telomerase activity (TA) and relative telomere length (TL) were detected and evaluated by real-time PCR. Apoptosis rates were assessed by flow cytometric analysis. The results showed that all the drugs tested sensitized the esophageal squamous cell carcinoma (ESCC) cell lines to radiation through an increase in radiation-induced DNA damage and cell apoptosis, deregulation of TA and decreasing the shortened TL caused by radiation. Each of the drugs investigated (zidovudine, abacavir and lamivudine) could be used for sensitizing human esophageal cancer cell lines to radiation. Consequently, the present study supports the potential of these three drugs as therapeutic agents for the radiosensitization of esophageal squamous cell cancer.
\end{abstract}

\section{Introduction}

The results of cytogenetic studies indicate that telomeres are specific and complex structures localized at the end of the chromosome, without which the genome integrity could not be preserved. Telomeres are highly conserved among all eukaryotic chromosomes in humans and other vertebrates and consist

Correspondence to: Dr Yufeng Cheng, Department of Radiation Oncology, Qilu Hospital of Shandong University, 107 West Wenhua Road, Jinan, Shandong 250012, P.R. China

E-mail: qiluchengyufeng@163.com

Key words: zidovudine, abacavir, lamivudine, esophageal squamous cell carcinoma, radiosensitivity of simple tandem repeats, such as AGGGTT (1-3). Telomere shortening initiates cellular transformation through the induction of chromosomal instability (4). Telomerase is a ribonucleoprotein enzyme that enables the synthesis of telomeric DNA in eukaryotes. The human telomerase consists of human telomerase RNA (hTR), telomerase reverse transcriptase (hTERT) and the accessory proteins dyskerin, NOP10, NHP2 and GAR1 (5). Telomerase activity (TA) level is positively associated with cell proliferation in most cancer cell types and renewal of tissues $(6,7)$. Telomerase maintains telomere length (TL) homeostasis and allows cancer cells to escape the antiproliferative obstacles caused by short telomeres (8).

Esophageal carcinoma is the seventh most common cancer and the fifth leading cause of cancer-related deaths in developing countries. Esophageal squamous cell carcinoma (ESCC) and adenocarcinoma are the two main types of esophageal cancer. In the highest-risk region, which extends from Northern Iran through the Central Asian to North-Central China, $90 \%$ of the cases are ESCC, contrasting to only $26 \%$ in the US (9). Currently, surgery, radiotherapy and chemotherapy remain the three mainstays in the treatment of ESCC, and therapy is best achieved by a multidisciplinary approach. Radiotherapy has played a critical role in the management of unresectable esophageal carcinoma (10). Nevertheless, intrinsic radioresistance accounts for the high recurrence and poor 5-year survival of ESCC patients (11). As in many other types of cancer, esophageal cancer cells have a reduced TL, and evidence has demonstrated that telomerase contributes to telomere maintenance, DNA repair, and the survival of esophageal cancer cells $(12,13)$. This indicates that telomerase could be a target for the induction of enhanced sensitivity of esophageal cancer cells to radiation.

The common medications used in highly active antiretroviral therapy (HAART) for AIDS, zidovudine, abacavir and lamivudine, are frequently used in anti-AIDS treatment. In addition, the embedding of virus in DNA and telomere lengthening are both courses of reverse transcription. Short telomeres induce hypersensitivity to ionizing radiation in mammals $(14,15)$. Zhou et al reported that zidovudine exerts a radiosensitization effect on human malignant glioma cells by inhibiting the activity of telomerase (16). To date, there are few reported experiments providing evidence that lamivudine and abacavir could be radiosensitizers of cancer cell lines. However, zidovudine, lamivudine and abacavir significantly inhibited TA in activated peripheral blood mononuclear 
cells in vitro (17). In the present study, we hypothesized that zidovudine, abacavir and lamivudine could all be used as radiosensitizers for ESCC cells.

In the present study, we investigated the action of zidovudine, abacavir and lamivudine in ESCC cell lines, either used as a single therapeutic agent or in combination with radiation, and determined clonogenic survival fraction, DNA damage, TA, TL and cell apoptosis. Through this process, we attempted to ellucidate the mechanism for achieving elevated sensitivity to radiation.

\section{Materials and methods}

Cell culture and reagents. Human ESCC cell line Eca109 [China Center for Type Culture Collection (CCTCC)] and Eca9706 [American Type Culture Collection (ATCC), Manassas, VA, USA] were cultured in RPMI-1640 medium supplemented with $10 \%$ calf serum (both from Gibco Life Technologies, Grand Island, NY, USA), and $100 \mathrm{U} / \mathrm{ml}$ penicillin $\mathrm{G}$ and streptomycin. Cells were incubated in a humidified atmosphere containing $5 \% \mathrm{CO}_{2}$ at $37^{\circ} \mathrm{C}$. Zidovudine, abacavir, and lamivudine are all reference material [National Institutes for Food and Drug Control (NIFDC) China].

Experimental grouping. Experimental grouping was carried out as folows: i) phosphate-buffered saline (PBS) control group, without the application of drugs and radiation; ii) radiation group, cells exposed to radiation; iii) drug groups, treated respectively with zidovudine $(0.02 \mathrm{mM})$, abacavir $(0.03 \mathrm{mM})$ and lamivudine $(0.025 \mathrm{mM})$ for $48 \mathrm{~h}$; clonal efficiency assay was used for concentration screening of zidovudine, abacavir and lamivudine, and $\mathrm{IC}_{20}$ concentrations were selected for our assays; iv) radiation and drug combination groups, exposure to radiation after administration of the respective drug doses for $48 \mathrm{~h}$.

Clonal efficiency assay. Eca109 and Eca9706 cells were seeded in 6-well plates at various cell densities for the different radiation doses $(0,2,4,6$ and $8 \mathrm{~Gy})$. A medical linear accelerator (Varian Clinac 23 EX; USA) was used to irradiate the cells for determination of clonogenic cell survival. Cells were incubated with or without zidovudine, abacavir and lamivudine for $48 \mathrm{~h}$ in the $37^{\circ} \mathrm{C}$ incubator. After being irradiated at an average dose rate of $100 \mathrm{cGy} / \mathrm{min}$, the cells were incubated for 12 days, fixed with ethanol and stained by crystal violet. Clonogenic cells were defined as those containing at least 50 cells. The survival curves were obtained with GraphPad Prism 5 to establish the mean lethal dose (D0), quasi-threshold dose (Dq) and survival fractions at $2 \mathrm{~Gy}$ (SF2). The radiosensitivity was quantified by the sensitization enhancement ratio (SER).

DNA damage measurement. DNA damage was measured using OxiSelect ${ }^{\mathrm{TM}}$ comet assay kit (Cell Biolabs Inc., San Diego, CA, USA). We conducted alkaline electrophoresis to detect any single-stranded and double-stranded DNA breaks (SSBs and DSBs) according to the kit instructions. Cell samples were harvested and washed with PBS. Cell suspension was mixed with molten agarose before being transfered to the OxiSelect ${ }^{\mathrm{TM}}$ comet slide, and then $75 \mu 1$ of this mixture was added to the slides. The embedded cells were treated with lysis buffer at $4^{\circ} \mathrm{C}$ for $1 \mathrm{~h}$ which was then replaced with pre-chilled alkaline buffer and placed at $4^{\circ} \mathrm{C}$ for $30 \mathrm{~min}$. Finally, the samples were electrophoresed in a horizontal chamber to separate intact DNA from the damaged fractions. Following electrophoresis, the samples were dried, stained with Vista Green DNA Dye provided in the kit, and visualized by epifluorescence microscopy. At least 30 cells/slide were examined, and DNA damage was analyzed using the Comet Assay Software Project (CASP). To quantify the DNA damage, the tail moment was calculated as the product of the migration of the DNA as well as the relative amount of DNA in the tail.

DNA isolation. DNA isolation from the cell samples was performed with QIAamp ${ }^{\circledR}$ DNA Mini and Blood Mini kit (Qiagen, Duesseldorf, Germany) following the manufacturer's recommendations. Cells were harvested by cell scraper and washed with PBS. After resuspension in PBS to a final volume of $200 \mu \mathrm{l}, 20 \mu \mathrm{l}$ of proteinase $\mathrm{K}$ was added to each sample. Then, $200 \mu 1$ buffer AL was applied to the samples, which were afterwards incubated at $56^{\circ} \mathrm{C}$ for $10 \mathrm{~min}$. Aliquts of $200 \mu \mathrm{l}$ ethanol were added to the samples, and the mixtures were transfered to QIAamp Mini spin columns (in 2-ml collection tubes). Furthermore, these tubes were centrifuged at $6,000 \mathrm{xg}$ for $1 \mathrm{~min}$, the columns were placed in clean $2-\mathrm{ml}$ collection tubes, and $500 \mu \mathrm{l}$ of buffer AW1 was added to the columns. Next, the procedure was repeated. Finally, $500 \mu \mathrm{l}$ buffer AW2 was admixed to the columns, and centrifugation was performed at $20,000 \times \mathrm{g}$ for $3 \mathrm{~min}$. The columns were put in clean $1.5-\mathrm{ml}$ microcentrifuge tubes and were washed with distilled water. DNA concentration was determined using a spectrophotometer (DeNovix, Wilmington, DE, USA) and DNA samples were prepared for TL assessment.

Quantitative real-time RT-PCR analysis. One hour after exposure to radiation of $2 \mathrm{~Gy}$, TL of all the samples was assessed using SYBR-Green Real-Time PCR Master Mix (Toyobo, Osaka, Japan) by Bio-Rad Single Color Real-Time PCR system (Bio-Rad, Hercules, CA, USA). The synthesized primer sequences (Sangon Biotech, Shanghai, China) were as follows: Telo, 5'-GGTTTGTTTGGGTTTGGGTTTGGGTTTGGGTT TGGGTT-3' (forward primer) and Telo, 5'-GGCTTGCCTTA СССТTACСCTТАССCTTACCCT-3' (reverse primer); 36B4, 5'-CAGCAAGTGGGAAGGTGTAATCC-3' (forward primer) and 5'-CCCATTCTATCATCAACGGGTACAA-3' (reverse primer). Relative TL was calculated by the $2^{-\Delta \Delta c t}$ method.

The detection of TA was carried out $1 \mathrm{~h}$ later followed by a single dose of irradiation of $2 \mathrm{~Gy}$ via the TRAPeze ${ }^{\circledast}$ kit RT Telomerase Detection kit (Merck Millipore, Darmstadt, Germany), as recommended by the manufacturer. PCR amplification was run in Bio-Rad Single Color Real-Time PCR system. Standard curves obtained through the TSR8 quantitation control were included in the kit providing a technique for quantitation of TA relative to TSR8 product amplification. The linear equation derived from the data curve fit was employed to extrapolate arbitrary telomerase units relative to the TSR8 amplification using the experimental sample average $\mathrm{Ct}$ values.

Flow cytometric analysis of apoptosis. Eca109 and Eca9706 cells were plated and exposed to zidovudine, abacavir and 

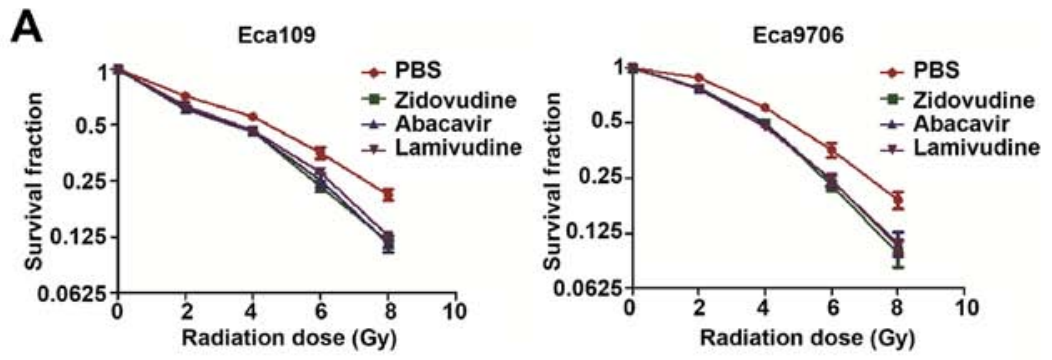

\section{B \\ Eca109}
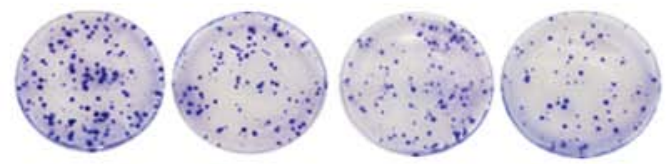

\section{Eca9706}
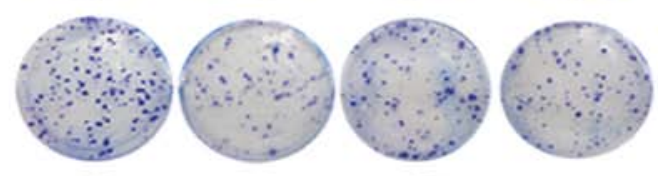
C
Eca109
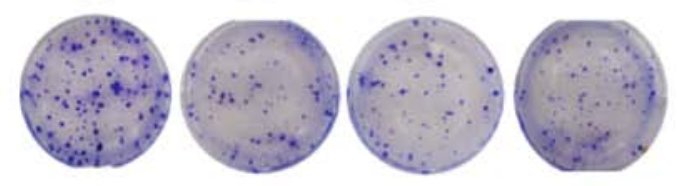

\section{Eca9706}
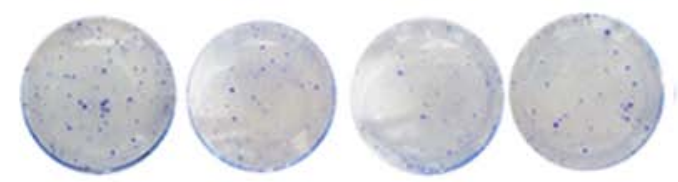

D Eca109
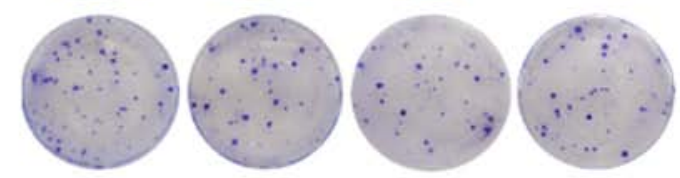

\section{Eca9706}
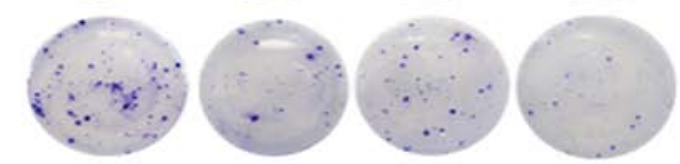

E Eca109
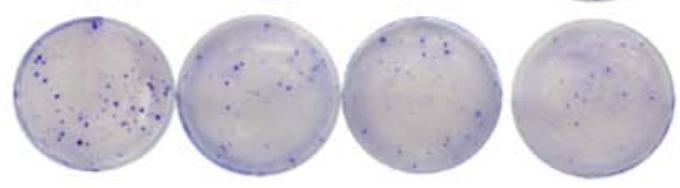

Eca9706
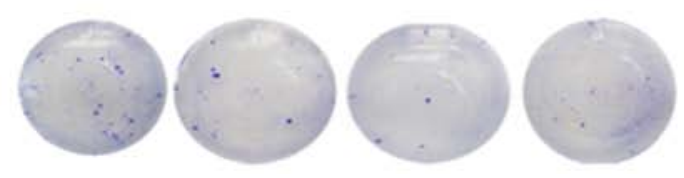

Figure 1. (A) Zidovudine, abacavir and lamivudine radiosensitize ESCC cell lines. After treatment with zidovudine, abacavir and lamivudine for 48 h, Eca109 and Eca9706 cells were irradiated at a single dose of $0,2,4,6$ or $8 \mathrm{~Gy}$. $\mathrm{P}<0.05$ for each radiation dose in combination with drugs vs. each radiation dose alone for both of the two cell lines. The clonogenic ability of the Eca109 and Eca9706 cell lines irradiated by a single dose of radiation was inhibited by zidovudine, abacavir and lamivudine. Zidovudine, abacavir and lamivudine sensitized the Eca109 and Eca9706 cancer cells to radiation, respectively, at the doses of (B) 2 , (C) 4, (D) 6 and (E) 8 Gy.

lamivudine for $48 \mathrm{~h}$ and then were irradiated with a single dose of $6 \mathrm{~Gy}$. Cells were collected $20 \mathrm{~h}$ after radiation, washed with cold $1 \mathrm{X}$ PBS, and apoptosis analysis was performed with the Annexin V-FITC apoptosis detection kit and then analyzed by flow cytometry (both from BD Biosciences, San Jose, CA, USA).

Statistical analysis. All data are presented as means \pm SD of three independent experiments and were analyzed using GraphPad Prism 5 software. Statistical analyses were performed using ANOVA with post hoc Tukey's test. Differences with P-value $<0.05$ were considered significant.

\section{Results}

Zidovudine, abacavir and lamivudine radiosensitize ESCC cells. To examine the effect of zidovudine, abacavir, and lamivudine on radiosensitization, clonogenic cell survival assays were performed in the Eca109 and Eca9706 cancer cells. The results of the clonal efficiency assay showed that treat- 
Table I. Radionsensitization effect of zidovudine, abacavir and lamivudine on Eca109 cells.

\begin{tabular}{lcccc}
\hline & D0 & Dq & SF2 & SER \\
\hline Radiation + PBS & $2.602 \pm 0.133$ & $2.769 \pm 0.086$ & $0.809 \pm 0.008$ & \\
Radiation + zidovudine & $2.168 \pm 0.085$ & $1.945 \pm 0.088$ & $0.682 \pm 0.010$ & $1.200 \pm 0.013$ \\
Radiation + abacavir & $2.208 \pm 0.183$ & $1.901 \pm 0.050$ & $0.678 \pm 0.005$ & $1.178 \pm 0.018$ \\
Radiation + lamivudine & $2.140 \pm 0.076$ & $1.930 \pm 0.183$ & $0.695 \pm 0.020$ & $1.216 \pm 0.016$ \\
\hline
\end{tabular}

Table II. Radiosensitization effect of zidovudine, abacavir and lamivudine on Eca9706 cells.

\begin{tabular}{lcccc}
\hline & $\mathrm{D} 0$ & $\mathrm{Dq}$ & $\mathrm{SF} 2$ & SER $_{\mathrm{D} 0}$ \\
\hline Radiation + PBS & $3.582 \pm 0.133$ & $2.882 \pm 0.086$ & $0.850 \pm 0.008$ & \\
Radiation + zidovudine & $3.279 \pm 0.085$ & $2.517 \pm 0.088$ & $0.815 \pm 0.010$ & $1.092 \pm 0.013$ \\
Radiation + abacavir & $3.374 \pm 0.183$ & $2.441 \pm 0.050$ & $0.810 \pm 0.005$ & $1.063 \pm 0.018$ \\
Radiation + lamivudine & $3.194 \pm 0.076$ & $2.325 \pm 0.183$ & $0.794 \pm 0.020$ & $1.121 \pm 0.016$ \\
\hline
\end{tabular}

$\mathrm{P}<0.05$, radiation vs. radiation + zidovudine, radiation + abacavir and radiation + lamivudine for the two cell lines. D0, indicates lethal dose; Dq, quasi-threshould dose; SF2, survival fractions at 2 Gy; SER, sensitization/enhancement ratio.

ment with zidovudine, abacavir and lamivudine substantially enhanced the radiation response in the Eca109 and Eca9706 cells (Fig. 1). We obtained D0, Dq, SF2 and SER ${ }_{D 0}$ by fitting the survival curves into the single-hit multi-target model $\mathrm{y}=1-\left[1-\mathrm{e}^{(-\mathrm{kx})}\right]^{\mathrm{N}}$. The characteristics of the survival curves of Eca109 and Eca9706 cells are presented in Tables I and II. The values of SF2 were 0.809 and 0.850 for Eca109 and Eca9706 cells. After the treatment with zidovudine, abacavir and lamivudine, SF2 values were $0.682,0.678$ and 0.695 in the the Eca109 cells and $0.815,0.810$ and 0.794 in the Eca9706 cells, respectively $(\mathrm{P}<0.05)$. The $\mathrm{SER}_{\mathrm{D} 0}$ data revealed that Eca109 cells were more sensitive to the action of these three drugs than Eca9706 cancer cells. These results indicated that zidovudine, abacavir and lamivudine may be used as radiosensitizers to improve the anticancer effect of radiotherapy.

Increase in post-irradiation DNA damage is induced by zidovudine, abacavir and lamivudine. The comet assay was used to measure DNA damage. The values of tolomere maintainence (TM) were calculated by CASPLab (Fig. 2). Higher values of TM were obtained in the drug and radiation groups than these values in the radiation-only group in both the Eca109 and Eca9706 cells $(\mathrm{P}<0.05)$. However, there was no difference in the values of TM following treatment with any two of the agents, zidovudine, abacavir and lamivudine ( $P>0.05)$. This experiment demonstrated that zidovudine, abacavir and lamivudine increased the DNA damage of irradiated Eca109 and Eca9706 cancer cells.

Inhibition of TA by zidovudine, abacavir and lamivudine. TA from the cell extracts was evaluated by the linear equation acquired from the curve fit using the amplification data from different concentrations of TSR8. The copy number was used to denote the TA of the experimental groups (Fig. 3). Compared to the PBS control group, TA of the Eca109 and
Eca9706 cells was upregulated by radiation but was downregulated by zidovudine, abacavir and lamivudine. For the drug groups, the ratios of TA inhibition were 54.8, 54.5 and $51.9 \%$ in the Eca109 cells $(\mathrm{P}<0.05)$, and $62.5,63.1$ and $63.3 \%$ in the Eca9706 cells $(\mathrm{P}<0.05)$. TA of the radiation-only group was increased by 27.3 and $10.1 \%$ compared with that of the Eca109 and Eca9706 cells in the PBS control group. The inhibition rates in the drug and radiation groups were 55.8, 54.8 and $54.3 \%$ in Eca109 and 52.0, 54.7 and 53.3\% in Eca9706 cancer cells $(\mathrm{P}<0.05)$. It was obvious that TA of the Eca109 and Eca9706 cells was suppressed by the action of zidovudine, abacavir and lamivudine regardless of whether or not radiation was used.

Shortening of TL is induced by the administration of zidovudine, abacavir and lamivudine after radiation. The relative TL was measured by real-time PCR (Fig. 4). There was no difference between the PBS and drug groups, which demonstrated that zidovudine, abacavir and lamivudine did not inhibit telomere lengthening of the Eca109 (P>0.05) and Eca9706 cells $(\mathrm{P}>0.05)$ after the treatment with these drugs for $48 \mathrm{~h}$. When combined with radiation, the TL in the radiation group $(\mathrm{P}=0.224$ in Eca109, $\mathrm{P}=0.413$ in Eca9706) and the radiation and drug groups $(\mathrm{P}<0.05$ for the three drugs in Eca109 and Eca9706 cells) was shorter than that in the PBS control group. Moreover, the radiation-only group exhibited higher values of TL than did the radiation and drug groups in the two cell lines, respectively $(\mathrm{P}<0.05)$. The results indicated that radiation decreased TL length, and the application of zidovudine, abacavir and lamivudine shortened TL additionally.

Zidovudine, abacavir and lamivudine radiosensitize ESCC cells through induction of apoptosis. The apoptosis ratios were significantly higher in the combination treatment groups than that in the radiation alone or following the 

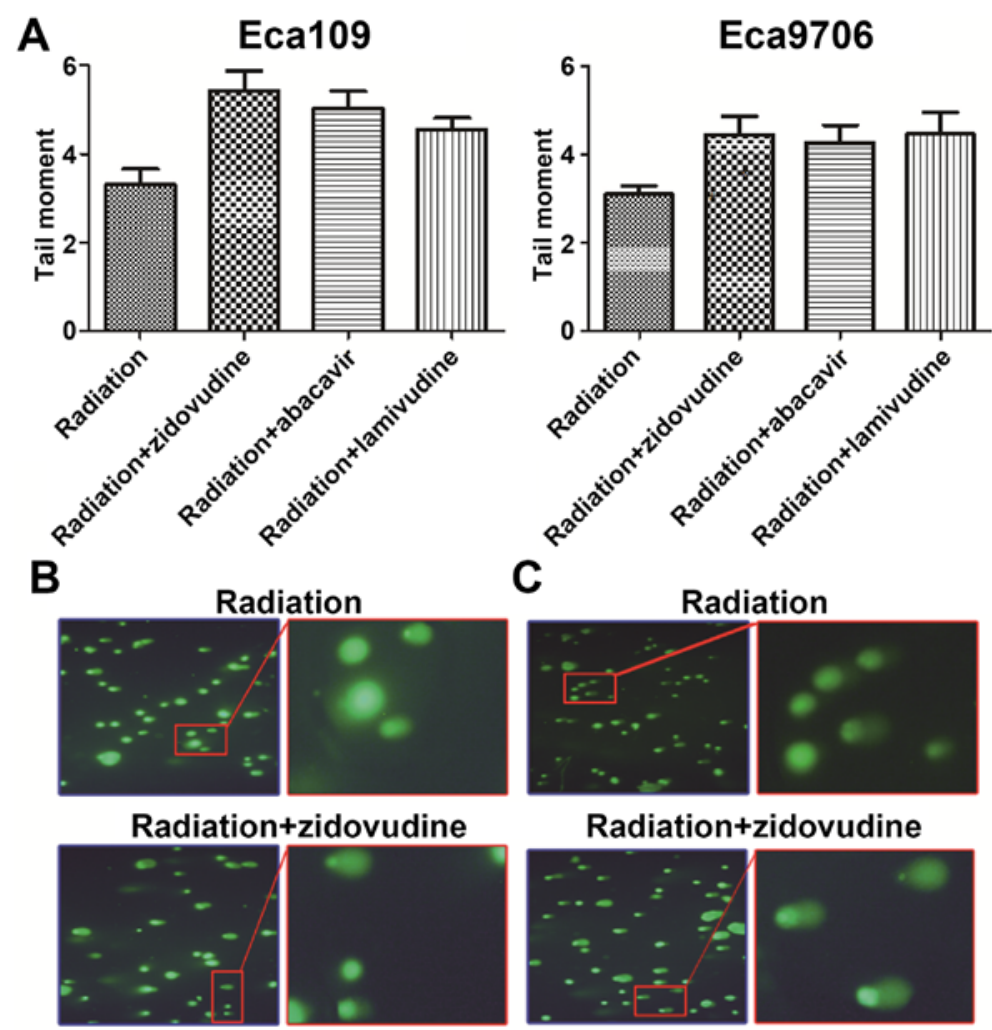

Radiation+zidovudine
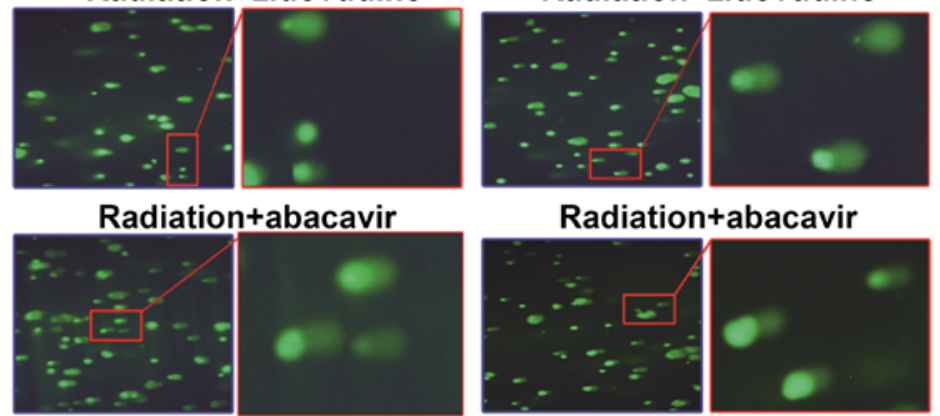

Radiation+lamivudine
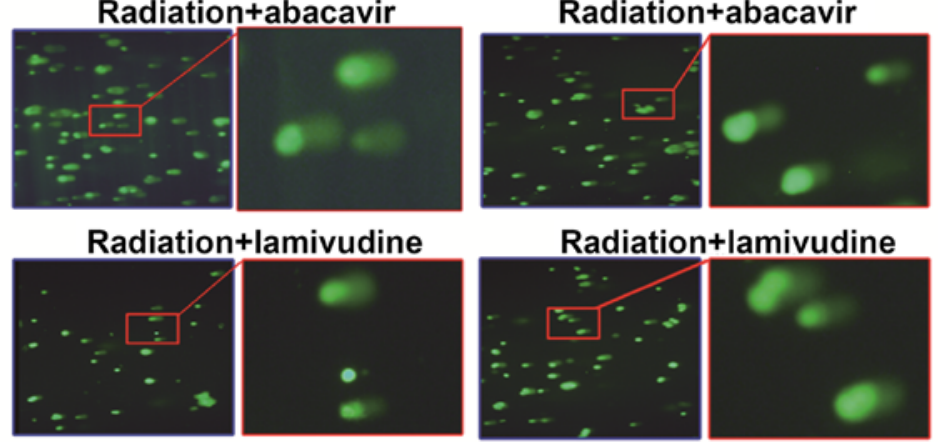

Figure 2. (A) Zidovudine, abacavir and lamivudine increased the DNA damage of irradiated Eca109 and Eca9706 cells. P<0.05, radiation vs. radiation + zidovudine, radiation + abacavir, and radiation + lamivudine for the two cell lines. (B and C) Comet assay images of Eca109 and Eca9706 cells.
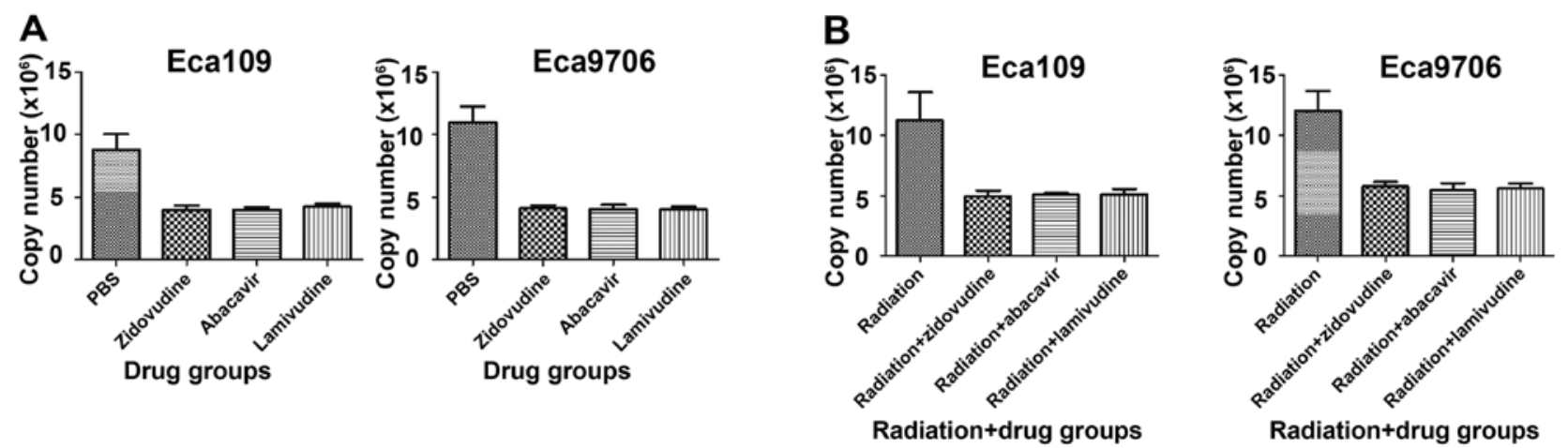

Figure 3. Telomerase activity (TA) of the Eca109 and Eca9706 cells was upregulated by radiation and was downregulated by these drugs whether irradiated or not. (A) Without the presence of radiation, zidovudine, abacavir and lamivudine inhibited TA in the Eca109 and Eca9706 cells ( $<<0.05)$. (B) The presence of radiation, zidovudine, abacavir and lamivudine caused downregulation of TA in the Eca109 and Eca9706 cells $(\mathrm{P}<0.05)$.

separate administration of zidovudine, abacavir and lamivudine (Fig. 5). Radiation induced cell apoptosis in $10.8 \%$ of Eca109 and in $9.5 \%$ of the Eca9706 cells. The individual treatments with zidovudine, abacavir and lamivudine in the Eca109 cells induced apoptosis rates of $~ 3.8,3.4$ and 3.4\%, respectively, whereas these values for Eca9706 cells were 2.8, 

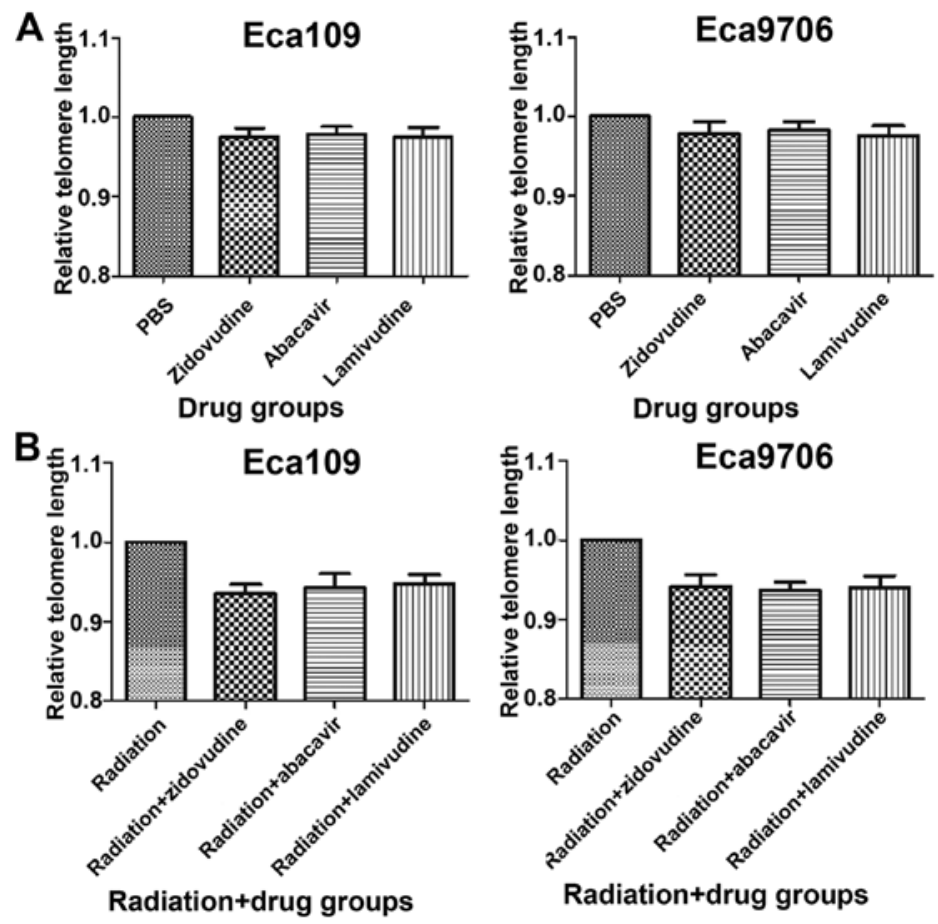

Figure 4. Zidovudine, abacavir and lamivudine did not reduce tolomere length (TL) in a short period of time (48 $\mathrm{h}$ ), whereas their further action enhanced radiation-induced TL shortening. (A) There was no difference between the PBS group and drug groups $(\mathrm{P}>0.05)$. (B) When combined with radiation, the TL in either the radiation group or the radiation and drug groups was shorter than that in the PBS control group $(\mathrm{P}<0.05)$.

A
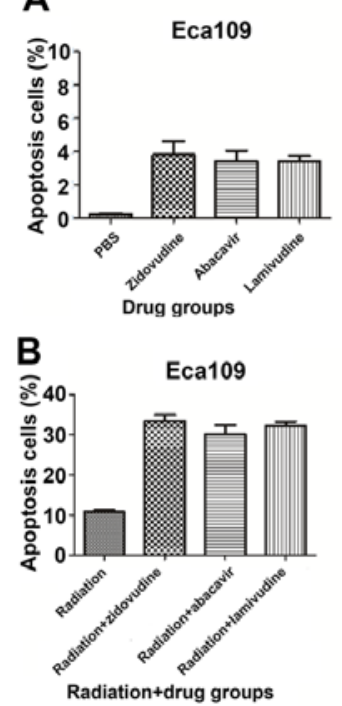
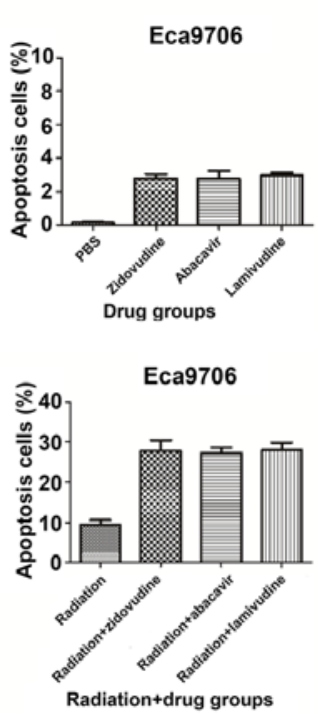

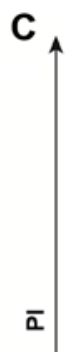

$\bar{a}$

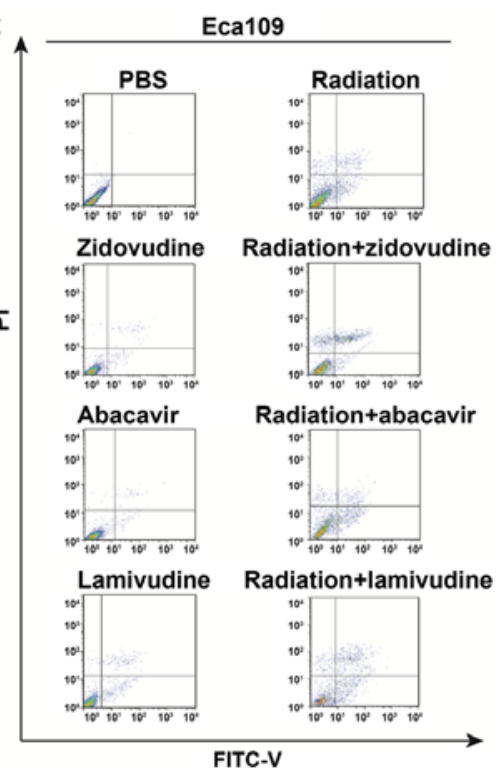

D

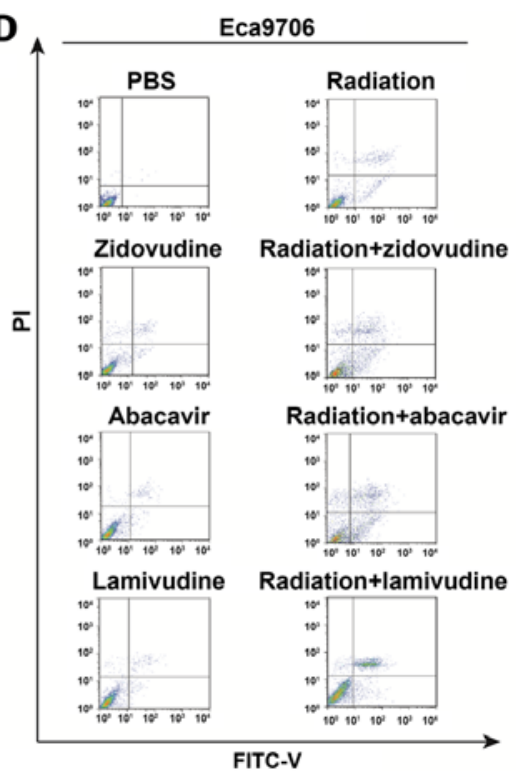

Figure 5. Zidovudine, abacavir and lamivudine increase the apoptosis rates in Eca109 and Eca9706 cells. (A) Following treatment of the three drugs alone, higher apoptosis rates were observed compared to the PBS control group in the Eca109 and Eca9706 cells $(\mathrm{P}<0.05)$. (B) Apoptosis rates were significantly increased by zidovudine, abacavir and lamivudine when combined with radiation $(\mathrm{P}<0.05)$. (C and $\mathrm{D})$ Representative outcomes of flow cytometric analysis for the Eca109 and Eca9706 cancer cells.

2.7 and $3.0 \%$. The combination of radiation and zidovudine, abacavir and lamivudine caused an increase in the apoptosis rates, and they reached values of $33.5,30.2$ and $32.2 \%$ in the Eca109 cells, and 27.8, 27.2 and $27.9 \%$ in the Eca9706 cells, correspondingly, which were significantly higher than those in the radiation-only group $(\mathrm{P}<0.05)$. These results indicated that zidovudine, abacavir and lamivudine sensitize Eca109 and Eca9706 to radiation by stimulating cell apoptosis.

\section{Discussion}

Radiotherapy plays a critical role in the treatment of esophageal cancer. Radioresistance has significantly decreased the efficacy of radiotherapy for esophageal cancer therapy (18). Our experimental results indicated that the combined treatment with zidovudine, abacavir and lamivudine significantly improved the efficacy of radiotherapy. We first observed that 
in combination with radiation doses of 2, 4, 6 and $8 \mathrm{~Gy}$, zidovudine, abacavir and lamivudine decreased the colony forming efficiency of the Eca109 and Eca9706 cells. Consistent with the results of the clonal efficiency assay, the comet assay findings demonstrated that these drugs promoted DNA damage (including SSBs and DSBs) of irradiated ESCC cells. Wong et al reported that the radiosensitivity of the cells with dysfunctional telomeres was related to chromosomal massive fragmentation and aberrations (19). Moreover, irrespective of whether or not radiation was applied, telomerase activity (TA) was successfully inhibited by these drugs. Furthermore, the levels of TA in the groups with only radiation and drug treatment were higher than in those in the drug groups, confirming that the DNA damage induced by radiation can increase TA, and that telomerase protects DNA against double-stranded DNA (dsDNA)-damaging events $(20,21)$. However, in the absence of radiation, telomeres were not shortened by the application of zidovudine, abacavir and lamivudine. This result indicates that the inhibition of telomerase during a short period of time ( $48 \mathrm{~h}$ ) could not shorten telomeres significantly. Notably, telomere length (TL) was reduced when radiation was used in the treatments (combined with drugs or separately). This phenomenon may be explained by the findings of a previous investigation, in which the telomere was revealed as highly sensitive to radiation (22-24). Furthermore, apoptotic flow cytometric analysis demonstrated that zidovudine, abacavir and lamivudine sensitized ESCC cells to radiation by increasing apoptotic cell death. These results suggested that these three drugs could sensitize ESCC cells to radiotherapy via the possible mechanisms of increasing radiation-induced DNA damage, deregulating TA, decreasing shortened TL caused by radiation, and promoting the apoptosis of Eca109 and Eca9706 cancer cells.

Currently, research on radiosensitizers has been conducted through the mechanisms of hypoxia, topoisomerases, microtubules and caspases. Numerous of these examinations have performed well in pre-clinical trials, but information needs to be provided on the safety and practicability of these approaches in clinical trials (25). From another point of view, DNA damage response is a determinant of cancer outcome after radiotherapy (26), and telomerase dysfunction in mice imparted a radiosensitivity syndrome correlated with accelerated mortality (19). Consequently, a telomerase inhibitor could act as a radiosensitizer for maximizing the benefits of radiotherapy. It has been reported that curcumin could inhibit telomerase, shorten telomeres in glioblastoma and medulloblastoma cells, and enhance the radiation-induced inhibition of neuroblastoma cell survival through suppression of TA $(27,28)$. Additionally, the telomerase inhibitor imetelstat was found to exhibit similar effects on glioblastoma and esophageal cancer cells $(29,30)$. However, there is no sufficient evidence to describe the adverse drug reactions and potency in clinical trials.

New uses for an already approved drug could be a strategy for shortening the drug approval period. The most frequent drug-related adverse events of zidovudine were nausea, headache and fatigue (31). The negative effects of abacavir that have most often occurred are fatigue, nausea, vomiting, abdominal pain, diarrhea, headache, rash and dyspepsia. However, in a study, the most common treatment-limiting event was hyper- sensitivity reaction (31). As for lamivudine, increased serum transaminase activities, neutropenia and hyperactivity were the most frequent side-effects (31). All of these data were collected in an anti-virus clinical environment. Whether the adverse effects will be similar among cancer patients is uncertain. In order to use more effectively zidovudine, abacavir and lamivudine as radiosensitizers in clinical practice, we will carry out further in vivo studies to investigate their efficacy.

In conclusion, the present study demonstrated that the combination of zidovudine, abacavir and lamivudine exhibited pronounced effects on decreasing the colony formation ability and stimulating DNA damage of ESCC cells through TL shortening, TA reduction and promotion of apoptosis. Zidovudine, abacavir and lamivudine may be valuable when used as radiosensitizers for cancer radiotherapy.

\section{Acknowledgements}

The present study was performed through the support of the National Natural Science Fund (approval no. 81572958).

\section{References}

1. Martínez P and Blasco MA: Replicating through telomeres: A means to an end. Trends Biochem Sci 40: 504-515, 2015.

2. Blackburn EH: Structure and function of telomeres. Nature 350: 569-573, 1991.

3. Londoño-Vallejo JA and Wellinger RJ: Telomeres and telomerase dance to the rhythm of the cell cycle. Trends Biochem Sci 37: 391-399, 2012.

4. Günes C and Rudolph KL: The role of telomeres in stem cells and cancer. Cell 152: 390-393, 2013.

5. Schmidt JC and Cech TR: Human telomerase: Biogenesis, trafficking, recruitment, and activation. Genes Dev 29: 1095-1105, 2015.

6. Shay JW and Bacchetti S: A survey of telomerase activity in human cancer. Eur J Cancer 33: 787-791, 1997.

7. Artandi SE and DePinho RA: Telomeres and telomerase in cancer. Carcinogenesis 31: 9-18, 2010.

8. Xu L, Li S and Stohr BA: The role of telomere biology in cancer. Annu Rev Pathol 8: 49-78, 2013.

9. Torre LA, Bray F, Siegel RL, Ferlay J, Lortet-Tieulent J and Jemal A: Global cancer statistics, 2012. CA Cancer J Clin 65: 87-108, 2015

10. Pennathur A, Gibson MK, Jobe BA and Luketich JD: Oesophageal carcinoma. Lancet 381: 400-412, 2013.

11. Enzinger PC and Mayer RJ: Esophageal cancer. $\mathrm{N}$ Engl J Med 349: 2241-2252, 2003.

12. Zhang C, Chen X, Li L, Zhou Y, Wang C and Hou S: The association between telomere length and cancer prognosis: Evidence from a meta-analysis. PLoS One 10: e0133174, 2015.

13. Pal J, Gold JS, Munshi NC and Shammas MA: Biology of telomeres: Importance in etiology of esophageal cancer and as therapeutic target. Transl Res 162: 364-370, 2013.

14. Goytisolo FA, Samper E, Martín-Caballero J, Finnon P, Herrera E, Flores JM, Bouffler SD and Blasco MA: Short telomeres result in organismal hypersensitivity to ionizing radiation in mammals. $\mathbf{J}$ Exp Med 192: 1625-1636, 2000.

15. McCaul JA, Gordon KE, Clark LJ and Parkinson EK: Telomerase inhibition and the future management of head-and-neck cancer. Lancet Oncol 3: 280-288, 2002.

16. Zhou FX, Liao ZK, Dai J, Xiong J, Xie CH, Luo ZG, Liu SQ and Zhou YF: Radiosensitization effect of zidovudine on human malignant glioma cells. Biochem Biophys Res Commun 354: 351-356, 2007.

17. Leeansyah E, Cameron PU, Solomon A, Tennakoon S, Velayudham P, Gouillou M, Spelman T, Hearps A, Fairley C, Smit V, et al: Inhibition of telomerase activity by human immunodeficiency virus (HIV) nucleos(t)ide reverse transcriptase inhibitors: A potential factor contributing to HIV-associated accelerated aging. J Infect Dis 207: 1157-1165, 2013. 
18. Shridhar R, Almhanna K, Meredith KL, Biagioli MC, Chuong MD, Cruz A and Hoffe SE: Radiation therapy and esophageal cancer. Cancer Control 20: 97-110, 2013.

19. Wong KK, Chang S, Weiler SR, Ganesan S, Chaudhuri J, Zhu C, Artandi SE, Rudolph KL, Gottlieb GJ, Chin L, et al: Telomere dysfunction impairs DNA repair and enhances sensitivity to ionizing radiation. Nat Genet 26: 85-88, 2000.

20. Akiyama M, Ozaki K, Kawano T, Yamada O, Kawauchi K, Ida H and Yamada $\mathrm{H}$ : Telomerase activation as a repair response to radiation-induced DNA damage in Y79 retinoblastoma cells. Cancer Lett 340: 82-87, 2013.

21. Fleisig HB, Hukezalie KR, Thompson CA, Au-Yeung TT, Ludlow AT, Zhao CR and Wong JM: Telomerase reverse transcriptase expression protects transformed human cells against DNA-damaging agents, and increases tolerance to chromosomal instability. Oncogene 35: 218-227, 2016.

22. Zschenker O, Kulkarni A, Miller D, Reynolds GE, GrangerLocatelli M, Pottier G, Sabatier L and Murnane JP: Increased sensitivity of subtelomeric regions to DNA double-strand breaks in a human cancer cell line. DNA Repair 8: 886-900, 2009.

23. Bouffler SD, Blasco MA, Cox R and Smith PJ: Telomeric sequences, radiation sensitivity and genomic instability. Int $\mathrm{J}$ Radiat Biol 77: 995-1005, 2001.

24. Mirjolet C, Boidot R, Saliques S, Ghiringhelli F, Maingon P and Créhange G: The role of telomeres in predicting individual radiosensitivity of patients with cancer in the era of personalized radiotherapy. Cancer Treat Rev 41: 354-360, 2015.

25. Wang Y, Sun C, Mao A, Zhang X, Zhou X, Wang Z and Zhang H: Radiosensitization to X-ray radiation by telomerase inhibitor MST-312 in human hepatoma HepG2 cells. Life Sci 123: 43-50, 2015.
26. Goldstein $\mathrm{M}$ and Kastan MB: The DNA damage response: Implications for tumor responses to radiation and chemotherapy. Annu Rev Med 66: 129-143, 2015.

27. Khaw AK, Hande MP, Kalthur G and Hande MP: Curcumin inhibits telomerase and induces telomere shortening and apoptosis in brain tumour cells. J Cell Biochem 114: 1257-1270, 2013.

28. Aravindan N, Veeraraghavan J, Madhusoodhanan R, Herman TS and Natarajan M: Curcumin regulates low-linear energy transfer $\gamma$-radiation-induced NFKB-dependent telomerase activity in human neuroblastoma cells. Int J Radiat Oncol Biol Phys 79: 1206-1215, 2011

29. Ferrandon S, Malleval C, El Hamdani B, Battiston-Montagne P, Bolbos R, Langlois JB, Manas P, Gryaznov SM, Alphonse G, Honnorat $\mathrm{J}$, et al: Telomerase inhibition improves tumor response to radiotherapy in a murine orthotopic model of human glioblastoma. Mol Cancer 14: 134, 2015.

30. Wu X, Smavadati S, Nordfjäll K, Karlsson K, Qvarnström F, Simonsson M, Bergqvist M, Gryaznov S, Ekman S and PaulssonKarlsson Y: Telomerase antagonist imetelstat inhibits esophageal cancer cell growth and increases radiation-induced DNA breaks. Biochim Biophys Acta 1823: 2130-2135, 2012.

31. Aronson JK and Dukes MNG (eds): Meyler's side effects of drugs: The international encyclopedia of adverse drug reactions and interactions. Elsevier, Amsterdam, Boston, 2006. 